\title{
MORFOLOGIA DOS FRUTOS, SEMENTES E PLÂNTULAS DE Platonia insignis MART. (CLUSIACEAE). III GERMINAÇÃO E PLÂNTULAS ${ }^{1}$
}

\author{
Káthia Socorro Mathias MOURÃ ${ }^{2}$, Celia Massa BELTRATT ${ }^{3}$
}

\begin{abstract}
RESUMO - São apresentados aspectos morfológicos das plântulas em desenvolvimento de Platonia insignis Mart.. A plântula é criptocotiledonar, hipógea A raiz é axial e no epicótilo, desenvolvemse 2-5 pares de catáfilos opostos, antes do aparecimento do primeiro par de metáfilos. Estes são simples, de disposição oposta cruzada, elípticos, tendo pecíolos curtos, com duas minúsculas alas; a venação é pinada, camptódroma, fortemente broquidódroma.
\end{abstract}

Palavras-chaves: Platonia insignis Mart.; germinação; plântula

Fruit, Seed and Seedling Morphology of Platonia insignis Mart. (Clusiaceae). III. Germination and Seedling.

SUMARY - Morphological and developmental features of seedlings of Platonia insignis Mart. are here described. The seedling is cryptocotylar, hypogeal. The primary root is axial; opposite scale leaves (cataphylls) precede the foliage leaves (metaphylls) in the epicotyl. The metaphylls are simple, eliptic, decussate, short petiolate; venation pattern is pinnate, camptodromous, and strongly brochidodromous.

Key-words: Platonia insignis Mart.; germination; seedling

\section{INTRODUÇÃO}

A fase de plântula além de crítica é também pouco conhecida A capacidade de se reconhecerem, num dado momento, as plântulas e os estádios juvenis na mata, pode ser de grande valor para se estabelecer a dinâmica de populações dnesta mata, bem como o manejo silvicultural de muitas matas semelhantes. Além disso, pode servir como índice para o reconhecimento do estádio sucessional em que se encontra a mata, de acordo com a diversidade de espécies e os indivíduos que dominam o solo (AMO, 1979). A comparação de resultados sobre a velocidade de germinação de sementes, aliados ao de morfologia e desenvolvimento das plântulas, são muito úteis para os que trabalham em viveiros e para as pesquisas sobre armazenamento de sementes e regeneração de florestas (NG, 1973).

A combinação de características da semente e do adulto, na plântula, pode fornecer numerosos indícios para a identificação das espécies no campo e em amostras de sementes (NG, 1973; AMO, 1979; DUKE \& POLHILL, 1981; KUNIYOSHI, 1983; PARRA, 1984).

Revendo a literatura relativa aos caracteres morfológicos das plântulas de Clusiaceae, torna-se evidente a grande carência de estudos pormenorizados, especialmente no que se refere a $P$. insignis.

Parte da Dissertação de Mestrado da primeira autora. Projeto subvencionado pela CAPES e pela FAPEMA

2 Dpto. de Biologia, UEM, Av. Colombo, 5790, Maringá, PR. CEP: $87020-900$

3 Dpto, de Botânica, IB/UNESP, Caixa Postal: 199, Rio Claro, SP CEP: 13506-900 
MOURÃO \& BELTRATI (1985a; 1985b) realizaramum estudo morfo-anatômico detalhado dos frutos e sementes maduros desta espécie. Dando continuidade a estes trabalhos, no presente estudo foram determinadas as principais características das plântulas, visando sua identificação no campo.

\section{MATERIAL E MÉTODOS}

O material botânico utilizado no presente trabalho constou de frutos maduros coletados no Parque Estadual do Itapiracó, área sob a responsabilidade da Secretaria de Meio Ambiente e Turismo do Estado do Maranhão (SEMATUR), situada a $2^{\circ} 32^{\prime}$ de latitude sul e $44^{\circ} 17^{\prime}$ de longitude oeste, no município de São Luis (MA)

No estudo dos aspectos morfológicos da plântula, as sementes foram colocadas para germinarem sacos de plantio contendo uma mistura de três partes de terra e uma parte de esterco de curral. Foram utilizadas amostras de 100 sementes, sendo as plântulas mantidas em ambiente natural, em local aberto e parcialmente sombreado.

Foram feitas inicialmente observações mensais e depois trimestrais. Os diferentes estádios de desenvolvimento das plântula até o aparecimento das primeiras folhas definitivas foram descritos e ilustrados. As plântulas obtidas, em diferentes fases de desenvolvimento, foram em parte fixadas em F.A.A. $50 \%$
(JOHANSEN, 1940), para observações posteriores, sendo outra parte herborizada e depositada como documento taxonômico no Herbarium Rioclarense (HRCB) sob o $\mathrm{n}^{\circ} \mathrm{de}$ registro 14589.

Os termos utilizados na descrição das plântulas estão de acordo com TOMLINSON (1960), DUKE (1965; 1969) e MIQUEL (1987).

A seguinte técnica foi utilizada na diafanização dos metáfilos para estudos de venação: os metáfilos foram mergulhados em Hidróxido de Sódio a $5 \%$ e, depois, em solução aquosa de Hipoclorito de Sódio a $20 \%$, lavados, corados em Safranina Aquosa a $1 \%$, desidratados em série alcoólica, montados em gelatina glicerinada liquefeita a $40^{\circ} \mathrm{C}$ e as lâminas lutadas com esmalte incolor (adaptação das técnicas de HANDRO (1964) e FELIPPE \& ALENCASTRO (1966). A descrição da veneção seguiu a terminologia de HICKEY (1973; 1979).

As ilustrações das plântulas foram obtidas a partir de espécimes vivos.

\section{RESULTADOS}

\section{Aspectos da germinação}

$\mathrm{O}$ início da germinação torna-se visível cerca de um mês após a semeadura, quando emerge a raiz primária, de coloração amarelada, que cresce muito, e posteriormente se torna robusta. Apresenta raízes secundárias finas, e muitas lenticelas.

Com aproximadamente cinco a 
seis meses começa a crescer o epicótilo, permanecendo os dimunutos cotilédones no interior do tegumento da semente.

Em condições ambientais, obteve-se $95 \%$ de germinação.

\section{Morfologia e desenvolvimento da plântula}

O desenvolvimento da plântula pode ser observado através das Figuras 1 a 6 .

A plântula de Platonia insignis é criptocotiledonar, hipógea. A raiz é axial podendo-se observar, com cerca de três meses, a presença de raízes laterias, que posteriormente se tornam bastante ramificadas $\mathrm{O}$ epicótilo, após a sua emergência, cresce rapidamente mostrando coloração avermelhada. Antes do aparecimento do primeiro par de metáfilos, que ocorre com cerca de cinco a seis meses, desenvolvem-se 25 pares de catáfilos opostos, de aspecto membranáceo que, às vezes, podem se tornar esverdeados, expandindo-se ligeiramente. Em um dos exemplares estudados observou-se também presença de dois pares de catáfilos, entre o primeiro e o segundo par de metáfilos.

Os metáfilos são simples, de disposição oposta cruzaada, elípticos, providos de pecíolos curtos Inicialmente sua coloração é verdeacobreada, passando, posteriormente a verde brilhante.

Raízes adventícias podem surgir na base do epicótilo

\section{Morfologia e padrão de venação dos metáfilos}

A lâmina foliar é simétrica, elíptica, ápice e base agudos (Fig. 7) A margem é inteira, a textura é coriácea e a coloração verde-brilhante.

O pecíolo é curto, achatado ventralmente, com duas pequenas alas.

A venação é pinada, camptódroma, fortemente broquidóroma. A veia primária é robusta $(2,5 \%)$, de curso reto e não ramificada (Figs. 7 e 8 ).

As veias secundárias possuem o ângulo de emergência moderadamente agudo $\left(55^{\circ}\right)$ e uniforme do ápice até a base da lâmina. A espessura é fina e o curso reto, sendo ramificadas (Figs. 7 a 9).

O laço formado pelas veias secundárias fica forte e reto, dando origem a uma veia intramarginal, paralela à margem da folha, e onde as veias secundárias numerosas e muito próximas estão fusionadas Dessa veia intramarginal partem arcos terciários que nem sempre se unem aos superadjacentes (Figs. 7 e 9).

As veias terciárias têm um padrão casualmente reticulado, com ângulo de origem, na maioria agudo-obtuso (AO), podendo variar (Figs 7 a 9).

A venação de ordem superior é distinta. Veias casualmente orientadas (Figs. 8 a 10). As vênulas variam de simples curvadas a ramificadas de uma a várias vezes (Figs. 10 e 11). As aréolas têm desenvolvimento imperfeito, arranjo casual, forma irregular e tamanho grande (Figs. 8 a 11).

\section{DISCUSSÃO E CONCLUSÕES}

De acordo com a classificação de DUKE $(1976 ; 1969)$ a plântula de Platonia insignis é criptocotiledonar, isto 


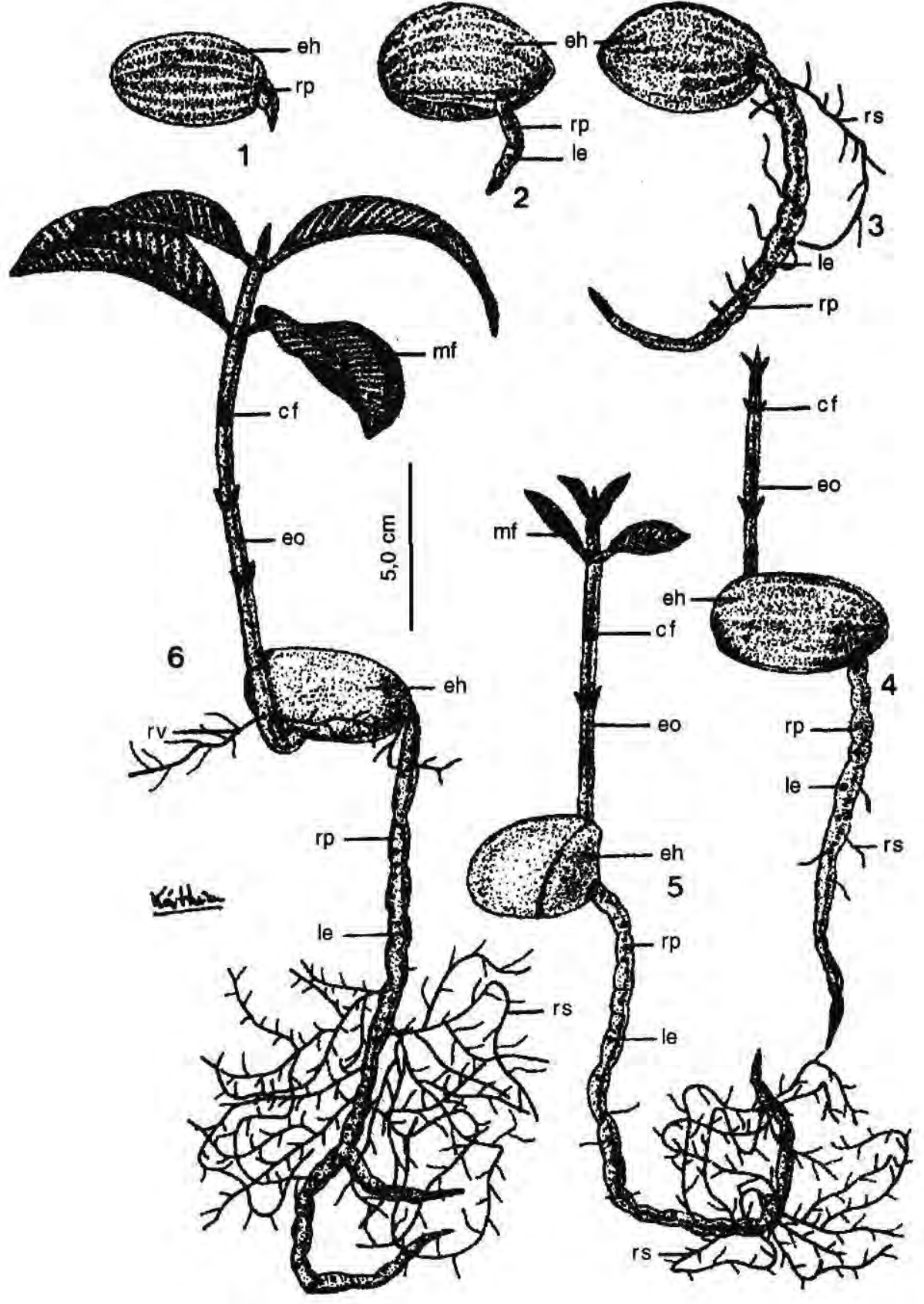

Figuras 1 a 6. Estádios sucessivos de desenvolvimento da plântula. 1 e 2: 1 mês (após a semeadura); $3: 3$ meses; 4 e 5: 6 meses; $6: 9$ meses (cf = catáfilo; eh = eixo hipocótilo-radicula; eo $=$ epicótilo; le = lenticela; $\mathrm{mf}=$ metáfilo; $\mathrm{rp}=$ raiz primária; $\mathrm{rs}=$ raiz secundária; $\mathrm{rv}$ = raiz adventícea) 

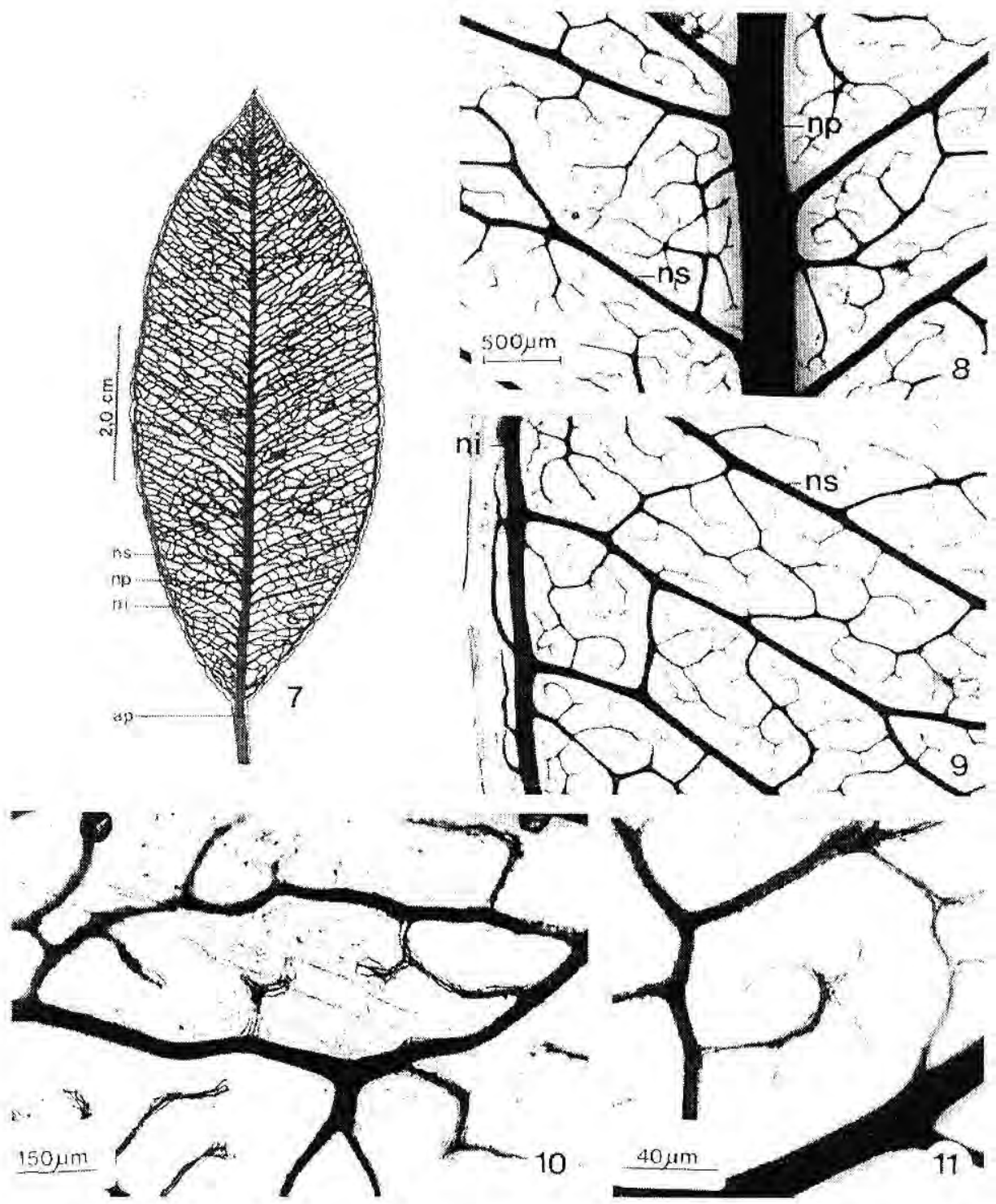

Figuras 7 a 11. Padrão de venaçāo do metáfilo 7: Aspecto geral da venação; 8: Detalhe da região da nervura central; 9: Detalhe da região marginal; 10: Detalhe de uma aréola; 11: Detalhe de uma vênula. $(\mathbf{a p}=$ ala peciolar; $\mathbf{n i}=$ nervura intramarginal; $\mathbf{n p}=$ nervura primária; $\mathbf{n s}=$ nervura secundária) 
é, os cotilédones permanecem no interior da testa, após a germinação Pela definição de MIQUEL (1987) a plântula dessa espécie enquadra-se no tipo "hipógea" (criptocotiledonar-hipógea).

No presente trabalho, para definir o estádio de plântula, pareceu mais adequado adotar-se o conceito de PARRA (1984), segundo o qual a fase de plântula é "a que transcorre,desde a germinção da semente, até o momento em que aparece o primeiro nomófilo com características semelhantes aos da planta-mãe".

MENSBRUGE (1966) obteve taxas variáveis de germinação em Clusiaceae, que considerou como: elevadas ( 80 a $90 \%$ ), em Mammea africana, Pentadesma butyracea, Garcinia gnetoides e $G$, polyantha; baixas (30 a 50\%), em $G$ kola e Symphonia globulifera; e muito baixa (10\%), em Allanblackia floribunda. Em P. insignis a taxa de germinação foi de $95 \%$ e portanto, pode ser considerada elevada.

De acordo com MENSBRUGE (1966), nas Clusiaceae por ele descritas, a germinação é sempre "hipógea", com as plântulas se caracterizando pela presença de um longo e espesso epicótilo, que apresenta catáfilos opostos; pelas duas primeiras folhas simples e opostas; e pela ausência de pêlos e de estípulas. Estas características estão presentes em $P$. insignis.

DUKE (1965) descreveu como criptocotiledonares as plântulas de Calophyllum calaba, Rheedia portoricensis e Garcinia mangostana. Para a família Clusiaceae DUKE (1965) citou as seguintes características gerais: plântula criptocotiledonar, cotilédones unilaterais, catáfilos supracotiledonares opostos, em todos os gêneros estudados, exceto Clusia, que apresenta germinação fanerocotiledonar, com cotilédones iguais. AMO (1979), para Rheedia edulis, e MIQUEL (1987), para Garcinia polyantha, Garcinia sp., Mammea africana e Pentadesma butyracea, citaram plântulas criptocotiledonares hipógeas.

En Platonia insignis foram observadas raízes adventíceas na bae do epicótilo, mas estas não chegam a substituir a raiz primária, como ocorre nas tribos Moronobeae e Garcinieae (PLANCHON \& TRIANA apud BRANDZA, 1908; BRANDZA, 1908; GUILLAUMIN, 1910); em todas as espécies de Clusiaceae descritas por MENSBRUGE (1966), com exceção de Allanblackia floribunda (tribo Moronobeae); e em Symphonia globulifera (MAURYLECHON et al., 1980).

A ocorrência de lenticelas na raiz primária de Mammea americana foi citada por BRANDZA (1908). Estas estruturas estão presentes também na raiz primária de $P$. insignis.

Quanto ao padrão geral de venação, as folhas da plântula são praticamente idênticas às da planta adulta (MOURÃO \& GIRNOS, 1994), enquadrando-se no padrão citado por HICHEY \& WOLFE (1975) para o Grupo "Ochnaceous", no qual está incluída a família Clusiaceae. $\mathrm{Na}$ classificação de MELVILLE (1976) está situado no tipo paxilato, cujo sinônimo é paralelódromo-transverso (MOUTON apud MELVILLE, 1976). 


\section{Bibliografia citada}

AMO, R.S. del 1979. Clave para plántulas y estados juveniles de especies primarias de una selva alta perennifolia en Veracruz, México. Biotropica, 4(2): 58-108

BRANDZA, G. 1908. Recherches anatomiques sur la germination des Hypéricacées et des Guttifères. Annales des Science Naturelles Bot., serie 9, 8: 221-300

DUKE, J.A. 1965. Keys for te identification of seedlings of some prominent wood species in eight forest types in Puerto Rico. Annals of the Missouri Botanical Gardens, 52(3): 314-350

DUKE, J.A. 1969. On tropical seedlings. I Seeds, seedlings, systems, and systematics. Annals of the Missouri Botanical Gardens, 56(2); 125-161

FELIPPE, G.M.; ALENCASTRO, F.M.M.R. 1966. Contribuição ao estudo da nervação foliar das compostas dos cerrados. I Tribos Helinieae, Heliantheae, Inuleae, Mutisieae e Senecioneae. Anais da Academia Brasileira de Ciências, 38(supl.): 125-158

GUILLAUMIN, A. 1910. L'etude des germinations appliquée à la classification des genres et a la phylogénie des groupes. Revue Générale de Botanique, 22: 449-468

HANDRO, W. 1964. Contribuiçăo ao estudo da venaçãoe anatomia foliar das amarantáceas dos cerrados Anais da Academia Brasileira de Ciências, 36(4): 479-499

HICKEY, L.J. 1973. Classification of the archtecture of dicotyledons leaves. American Journal of Botany, 60(1): 17-33

HICKEY, L.J. 1979. A revised classification of the archtecture of dicotyledons leaves. In: METCALFE, C.R. \& CHALK, L. (eds). Anatomy of Dicotyledons. 2 ed. Oxford, Claredon Press: 25-39

HICKEY, L.J.; WOLFE, J.A. 1975. The bases of Angiosperm phylogeny: vegetative morphology. Annals of Missouri Botanical Gardens, 62(3): 538-589
JOHANSEN, D.A. 1940. Plant microtechnique. McGraw-Hill Book, New York. 523 p.

MAURY-LECHON, G.; CORBINEAU, E.; CÔME, D. 1980. Données préliminaires sur la germination des graines et la conservation des plantules de Symphonia globulifera L.f. (Guttifere). Revue Bois et Forêts des Tropiques, 193: 35-40.

MELVILLE, R. 1976. The terminology of the leaf archtecture. Taxon, 25(5/6): 549-561

MENSBRUGE, G, de la. 1966. La germination et les plántules des essences arborées de la forêt dense humide de la Côte d'lvoire. Centre Technique Forestier Tropical, France. 389 p.

MIQUEL, S. 1987. Morphologie fonctionelle des plántules d'espèces forestières du Gabon. Bulletin du Muséum Nationale d'Histoire naturelle, série 4, n. 9, section $B$, Adansonia, 1: 101-121

MOURÄO, K.S.M.; GIRNOS, E.C. 1994. Estudo morfo-anatômico das folhas de Platonia insignis Mart (Clusiaceae). Revista Brasileira de Biologia, 54(1): 101-110

MOURÃO, K.S.M.; BELLTRATI, C.M. 1995a. Morfologia dos frutos, sementes e plântulas de Platonia insignis Mart (Clusiaceae). 1. Aspectos anatômicos dos frutos e sementes em desenvolvimento. Acta Amazonica, 25(1/2); 11-32

MOURĀO, K.S.M.; BELLTRATI, C.M. 1995b. Morfologia dos frutos, sementes e plântulas de Platonia insignis Mart (Clusiaceae).II. Morfo-anatomia dos frutos e sementes maduros. Acta Amazonica, 25(1/2): 33-46

NG, E.S.P. 1973. Germination of fresh seeds of Malaysian trees. The Malaysian Forester, 36(2): 54-65

PARRA, P. 1984. Estudio de la morfologia externa de plantulas de Calliandra gracilis, Mimosa albida, Mimosa carporum e Mimosa tenuiflora. Rev. Fac. Agron., Maracay, 13(1/4): 311-350

TOMLINSON, P.B. 1960. Seedling leaves in palms and their morphological significance. Journal of the Arnold Arboretum, 51: 414-428

Aceito para publicação em 08.02.95 